Supporting Information

\title{
Self-Optimized MOF Electrocatalysts with Structural Stability and High Current Tolerance for Water Oxidation
}

Chao-Peng Wang,,$^{\dagger}$ Yang Feng, ${ }^{\dagger}$ Hao Sun,$^{\dagger}$ Yurou Wang, ${ }^{\dagger}$ Jun Yin, ${ }^{\dagger}$ Zhenpeng Yao, ${ }^{*}, \dot{\dagger}, \S$ Xian-

He Bu, ${ }^{*, \dagger, l}$ and $\operatorname{Jian} Z h u^{*, \dagger, \|, \&}$

${ }^{\dagger}$ School of Materials Science and Engineering, National Institute for Advanced Materials, Nankai University, Tianjin 300350, P. R. China

Department of Chemistry and Chemical Biology, Harvard University, Cambridge, MA 02138 USA

${ }^{\S}$ Department of Chemistry and Department of Computer Science, University of Toronto, Toronto, Ontario M5S 3H6, Canada

ITianjin Key Laboratory of Metal and Molecule-Based Material Chemistry, Nankai University, Tianjin 300350, P. R. China

\&Tianjin Key Laboratory for Rare Earth Materials and Applications, Nankai University, Tianjin 300350, P. R. China

*E-mail:

yaozhenpeng@gmail.com; buxh@nankai.edu.cn; zj@nankai.edu.cn 


\section{Contents:}

\section{Chemicals}

\section{Figures}

S1. The photographs of nickel foam substrates before and after the hydrothermal reaction.

S2. FT-IR spectra of $\mathrm{H}_{2}$ TDC, Fe-MOFs, Ni-MOFs and FeNi-MOFs.

S3. Width distribution of FeNi-MOFs nanobelt arrays.

S4. HRTEM image of FeNi-MOF nanobelts.

S5. AFM image of FeNi-MOF nanobelt and the corresponding height profile.

S6. SEM image and SAED pattern of Ni-MOFs.

S7. AFM image of Ni-MOF nanobelt and the corresponding height profile.

S8. SEM image and SAED pattern of Fe-MOFs.

S9. AFM image of Fe-MOF nanobelt and the corresponding height profile.

S10. XRD patterns of FeNi-MOFs immersed in $1 \mathrm{M} \mathrm{KOH}$ solution for $5 \mathrm{~h}$ and $10 \mathrm{~h}$.

$\mathrm{S} 11$. XRD patterns of Fe-MOFs and Ni-MOFs immersed in $1 \mathrm{M} \mathrm{KOH}$ solution for $10 \mathrm{~h}$.

S12. Crystal structure of Ni-MOFs and Co-MOFs.

S13. SEM and EDS elemental mapping images of FeCo-MOFs.

S14. XRD patterns of Co-MOF, FeCo-MOF, FeNi-MOF nanoarrays and simulated data from the reported crystal structure.

S15. XRD patterns of FeCo-MOF nanoarrays immersed in $1 \mathrm{M} \mathrm{KOH}$ solution for $5 \mathrm{~h}$.

S16. Chronopotentiometric curve for FeNi-MOFs at a constant current density of $10 \mathrm{~mA} \mathrm{~cm} \mathrm{c}^{-2}$.

S17. CV curves for Fe-MOFs, Ni-MOFs and nickel foam in $1 \mathrm{M} \mathrm{KOH}$ solution.

S18. XRD patterns and High-resolution XPS spectra of Fe-MOFs and Ni-MOFs after different CV test.

S19. SEM and EDS elemental mapping images of $\mathrm{Fe}_{1} \mathrm{Ni}_{1}-\mathrm{MOFs}$.

S20. SEM and EDS elemental mapping images of $\mathrm{Fe}_{3} \mathrm{Ni}_{1}-\mathrm{MOFs}$.

$\mathrm{S} 21$. Polarization curves and the comparison of overpotentials for $\mathrm{Fe}_{1} \mathrm{Ni}_{1}-\mathrm{MOFs}, \mathrm{Fe}_{2} \mathrm{Ni}_{1}-\mathrm{MOFs}$ and $\mathrm{Fe}_{3} \mathrm{Ni}_{1}$-MOFs.

S22. CV curves of FeNi-MOFs, Fe-MOFs and Ni-MOFs measured at different scan rates from 20 to $100 \mathrm{mV} \mathrm{s}^{-1}$.

S23. SEM and the corresponding SAED images of FeNi-MOFs after long-term OER durability test.

S24. XRD, Raman and XPS spectra of FeNi-MOFs after long-term OER durability test.

S25. TEM image, SAED image, XRD and FT-IR spectra of FeNi-MOFs after $6 \mathrm{~h}$ OER process. 
Chemicals. Ferrous chloride tetrahydrate $\left(\mathrm{FeCl}_{2} \cdot 4 \mathrm{H}_{2} \mathrm{O}\right)$, nickel nitrate hexahydrate $\left(\mathrm{Ni}\left(\mathrm{NO}_{3}\right)_{2} \cdot 6 \mathrm{H}_{2} \mathrm{O}\right), \mathrm{NaOH}$ and commercial $\mathrm{RuO}_{2}$ were purchased from Sigma Aldrich. 2, 5thiophenedicarboxylic $\left(\mathrm{H}_{2} \mathrm{TDC}, 98 \%\right)$ was obtained from J\&K Scientific Ltd. All aqueous solutions were prepared using deionized water. All chemicals are analytical grade and used as received without further purification.

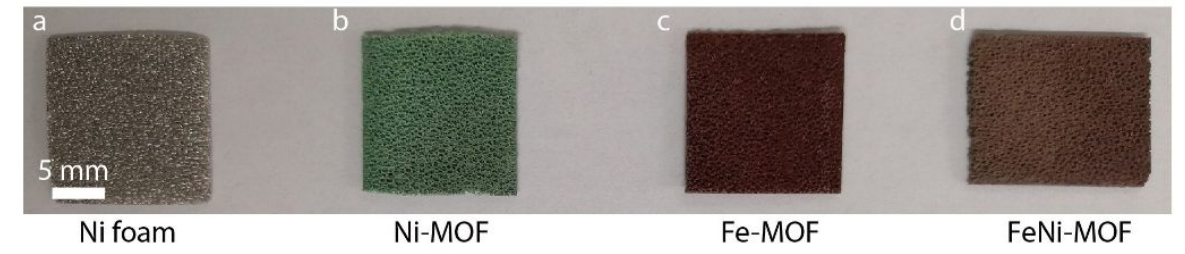

Figure S1. The photographs of a) Ni foam, b) Ni-MOFs, c) Fe-MOFs and d) FeNi-MOFs.

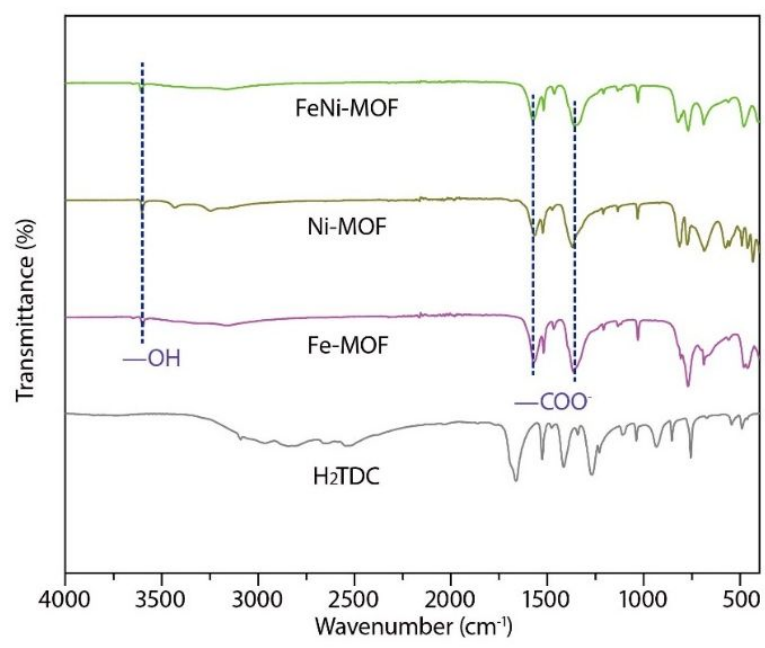

Figure S2. FT-IR spectra of $\mathrm{H}_{2}$ TDC, Fe-MOFs, Ni-MOFs and FeNi-MOFs.

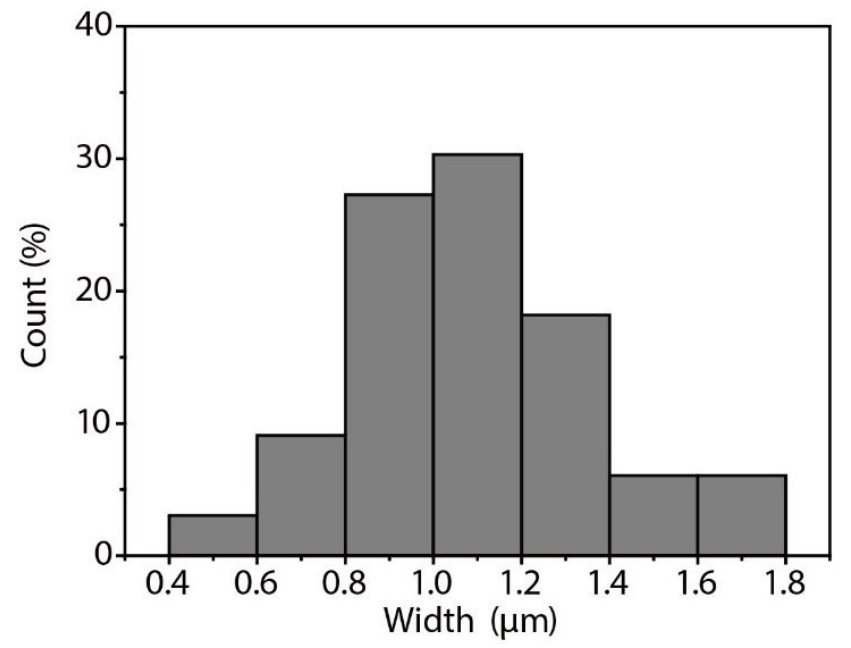

Figure S3. Width distribution of FeNi-MOFs nanobelt arrays. 


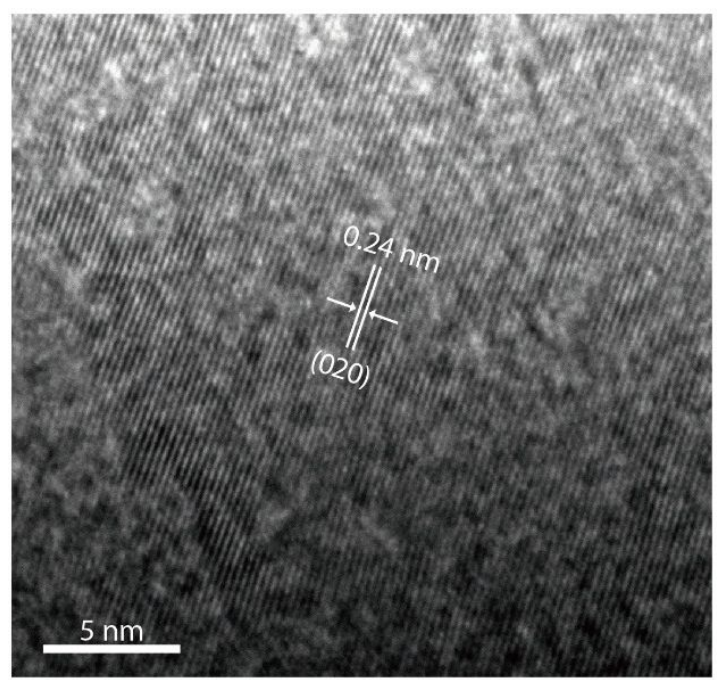

Figure S4. HRTEM image of FeNi-MOFs nanobelt.
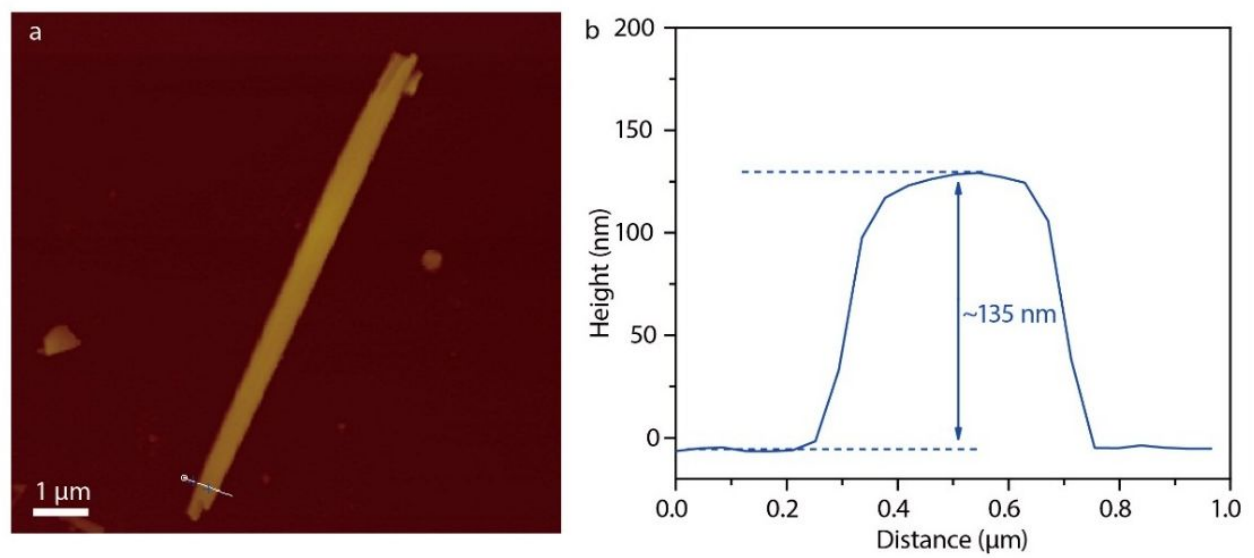

Figure S5. a) AFM image of FeNi-MOF nanobelt. b) The corresponding height profile showing the thickness of the FeNi-MOF nanobelt.

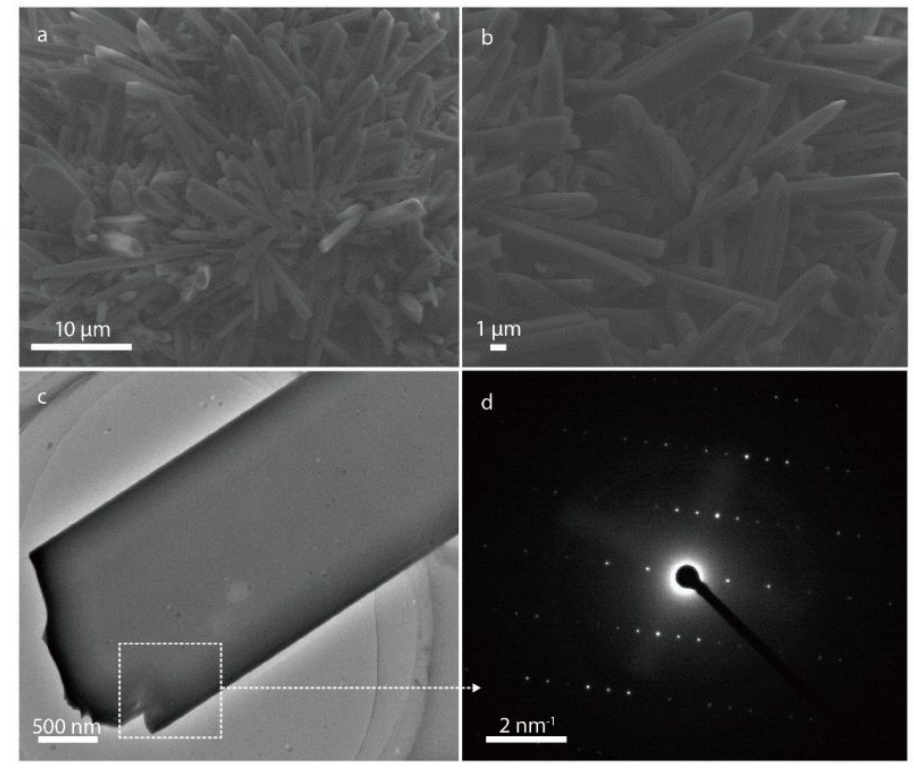

Figure S6. a, b) SEM images of Ni-MOF nanoarrays grown on nickel foam with different magnifications. c) TEM image and d) SAED pattern for Ni-MOFs. 

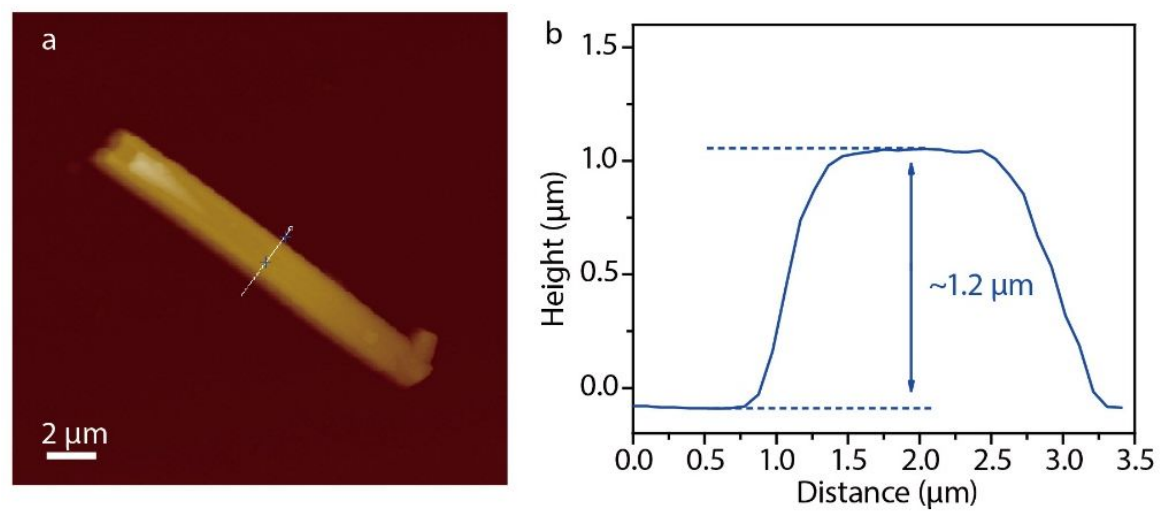

Figure S7. a) AFM image of Ni-MOF rod. b) The corresponding height profile showing the thickness of the Ni-MOF rod.

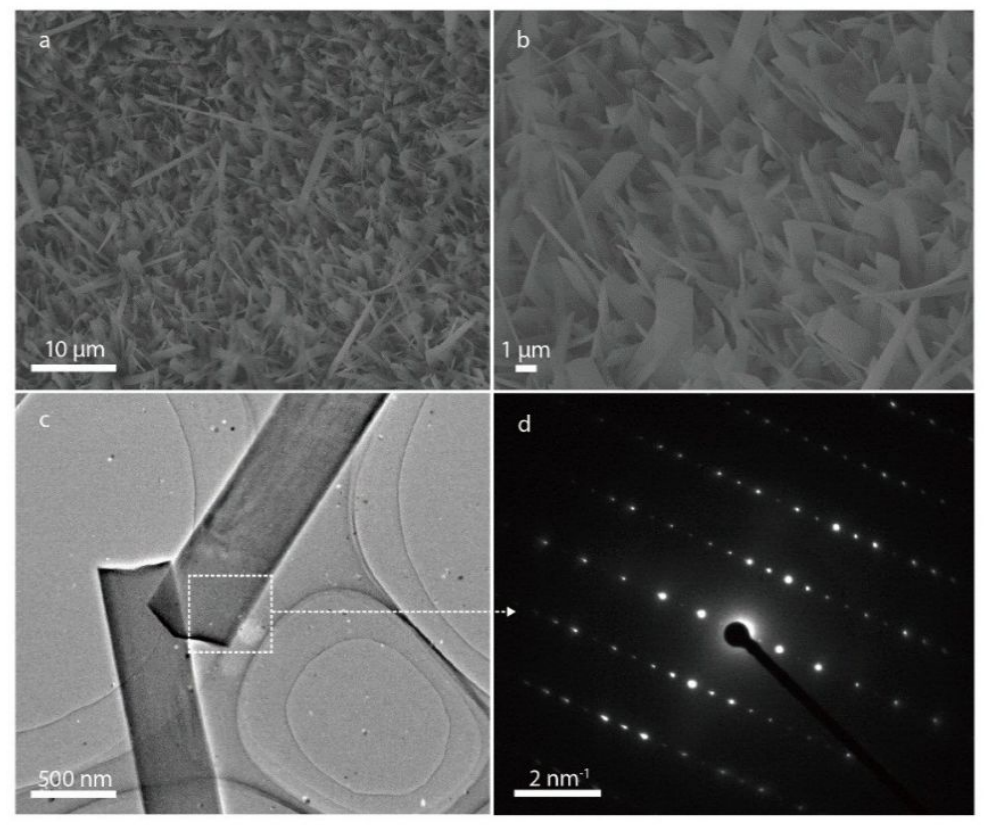

Figure S8. a, b) SEM images of Fe-MOF nanoarrays grown on nickel foam with different magnifications. c) TEM image and d) SAED pattern for Fe-MOFs.
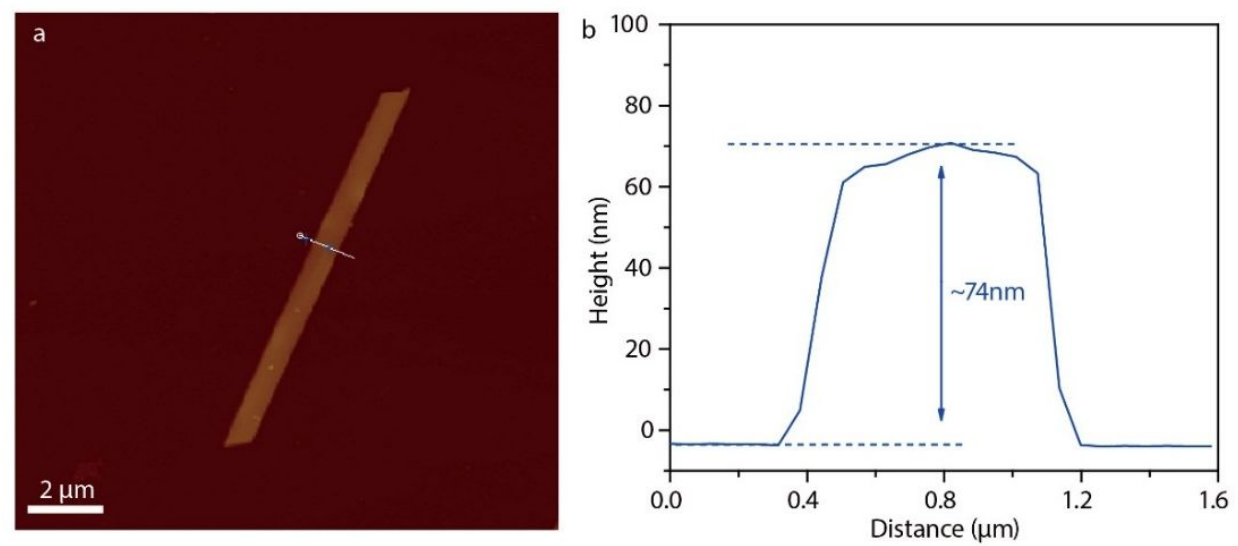

Figure S9. a) AFM image of Fe-MOF nanobelt. b) The corresponding height profile showing the thickness of the Fe-MOF nanobelt. 


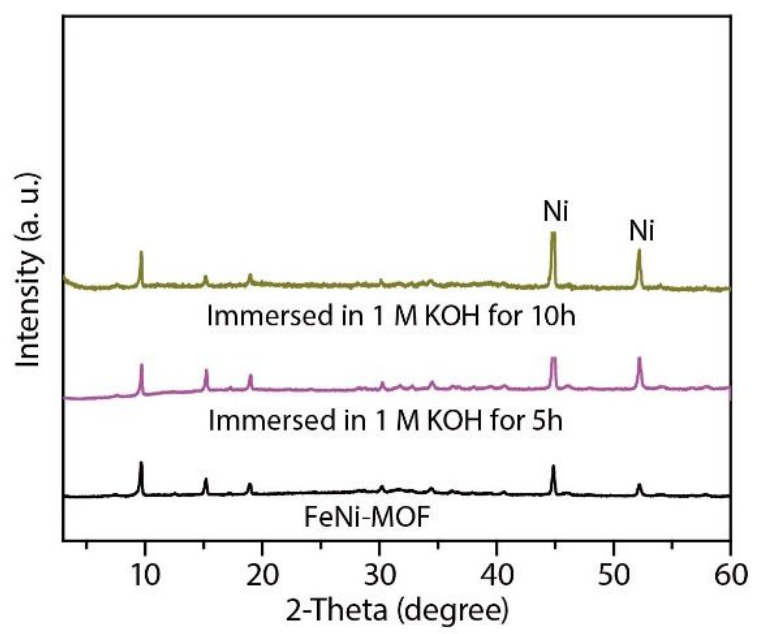

Figure S10. XRD patterns of FeNi-MOF nanoarrays immersed in $1 \mathrm{M} \mathrm{KOH}(\mathrm{pH}=14)$ for $5 \mathrm{~h}$ and $10 \mathrm{~h}$.

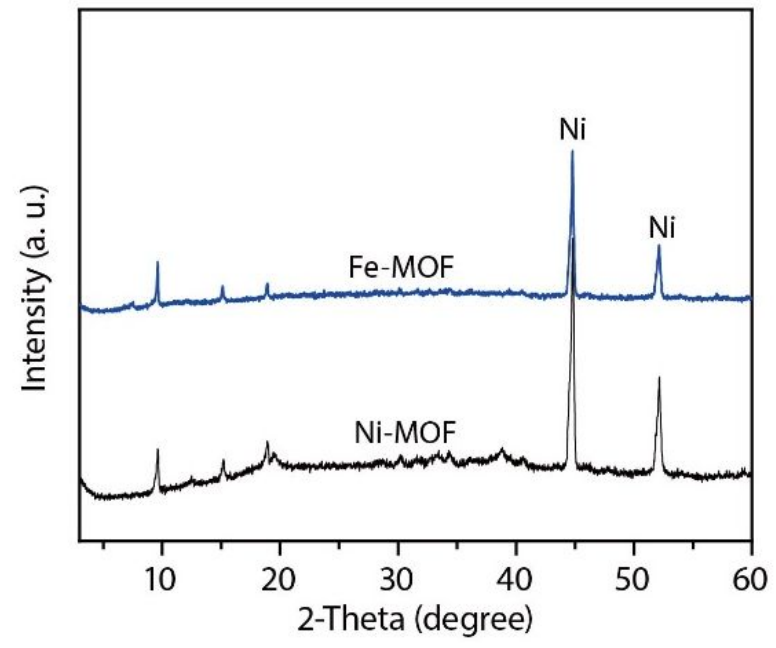

Figure S11. XRD patterns of Fe-MOF and Ni-MOF nanoarrays immersed in $1 \mathrm{M} \mathrm{KOH}(\mathrm{pH}=14)$ for $10 \mathrm{~h}$
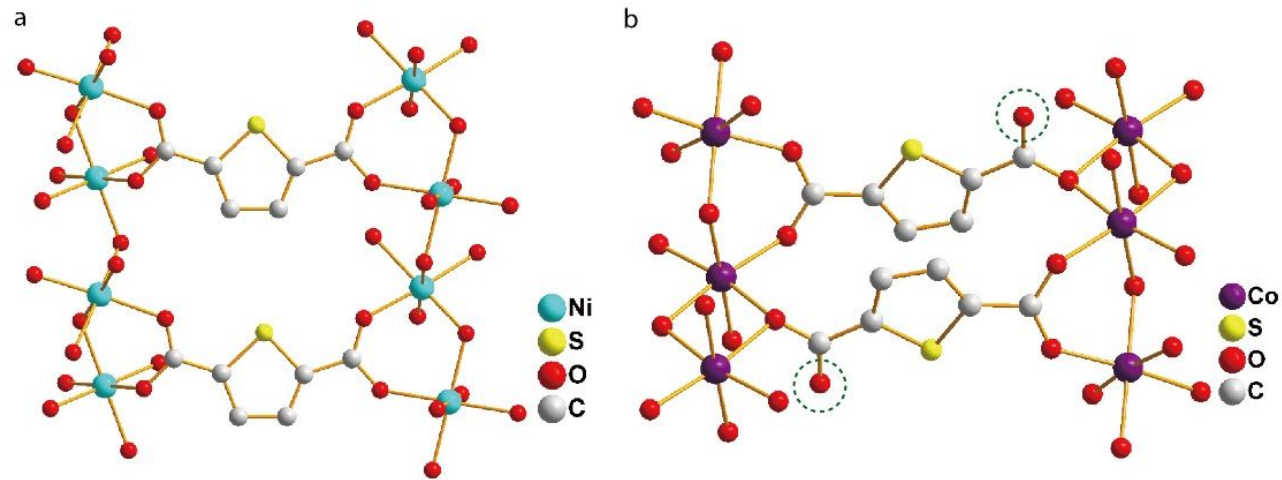

Figure S12. Crystal structure of a) Ni-MOFs and b) Co-MOFs. 


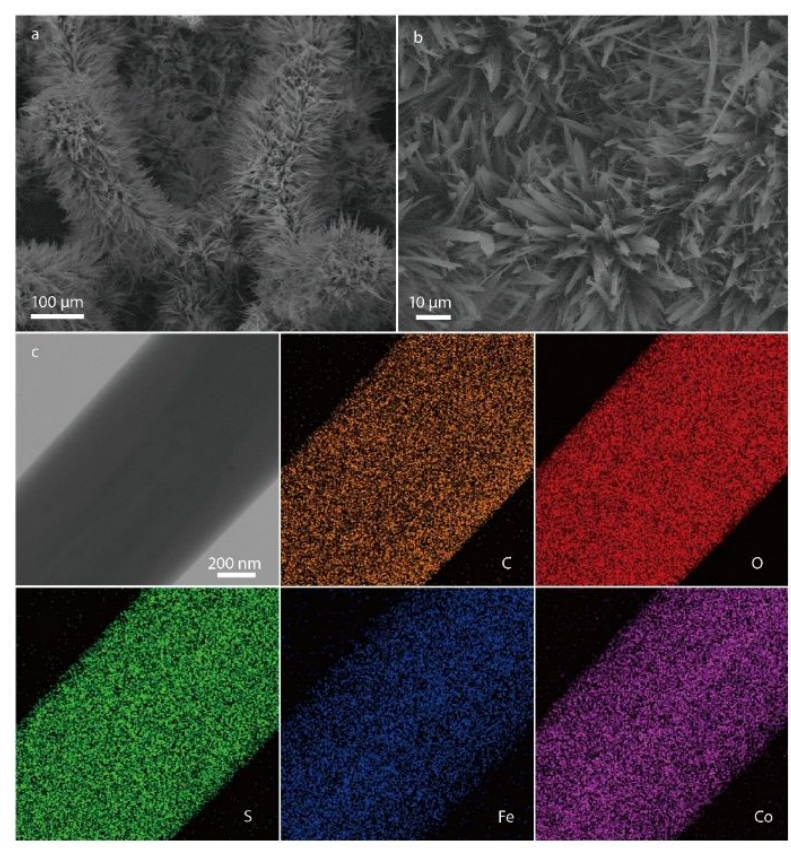

Figure S13. a, b) SEM images of FeCo-MOF nanoarrays grown on nickel foam with different magnifications. c) HAADF-STEM and the corresponding EDS elemental mapping images of $\mathrm{C}, \mathrm{O}, \mathrm{S}, \mathrm{Fe}$ and Co elements for FeCo-MOF nanobelts.

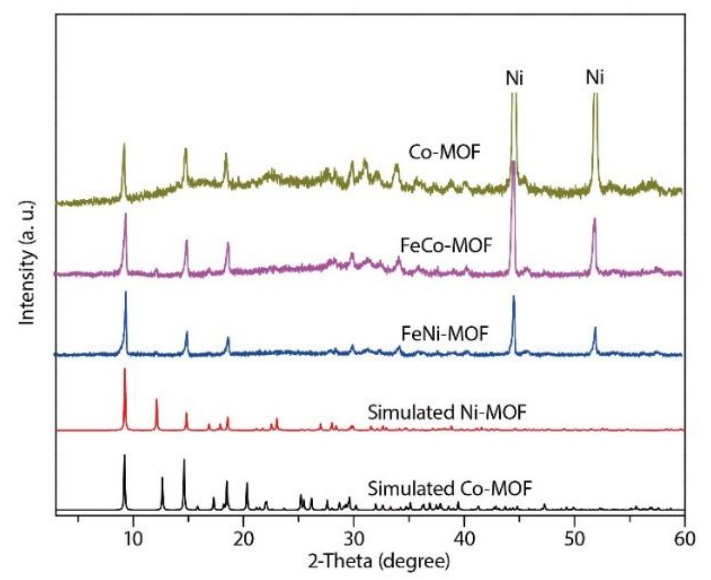

Figure S14. XRD patterns of Co-MOF, FeCo-MOF, FeNi-MOF nanoarrays and simulated data from the reported crystal structure.

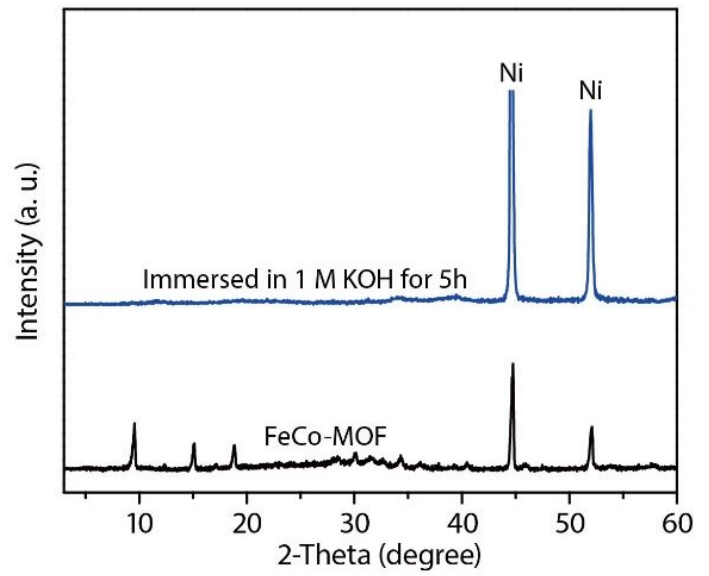

Figure S15. XRD patterns of FeCo-MOF nanoarrays immersed in $1 \mathrm{M} \mathrm{KOH}(\mathrm{pH}=14)$ for $5 \mathrm{~h}$. 


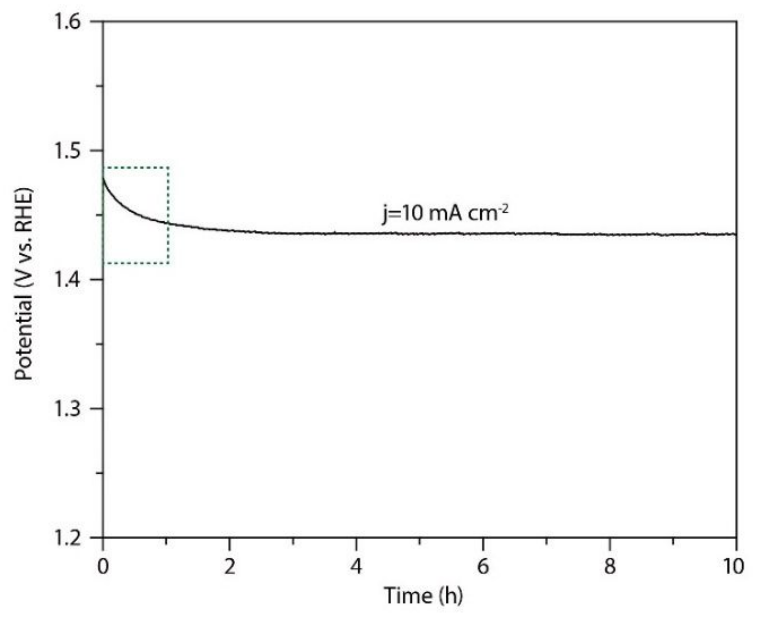

Figure S16. Chronopotentiometric curve for FeNi-MOFs at a constant current density of 10 $\mathrm{mA} \mathrm{cm}{ }^{-2}$.
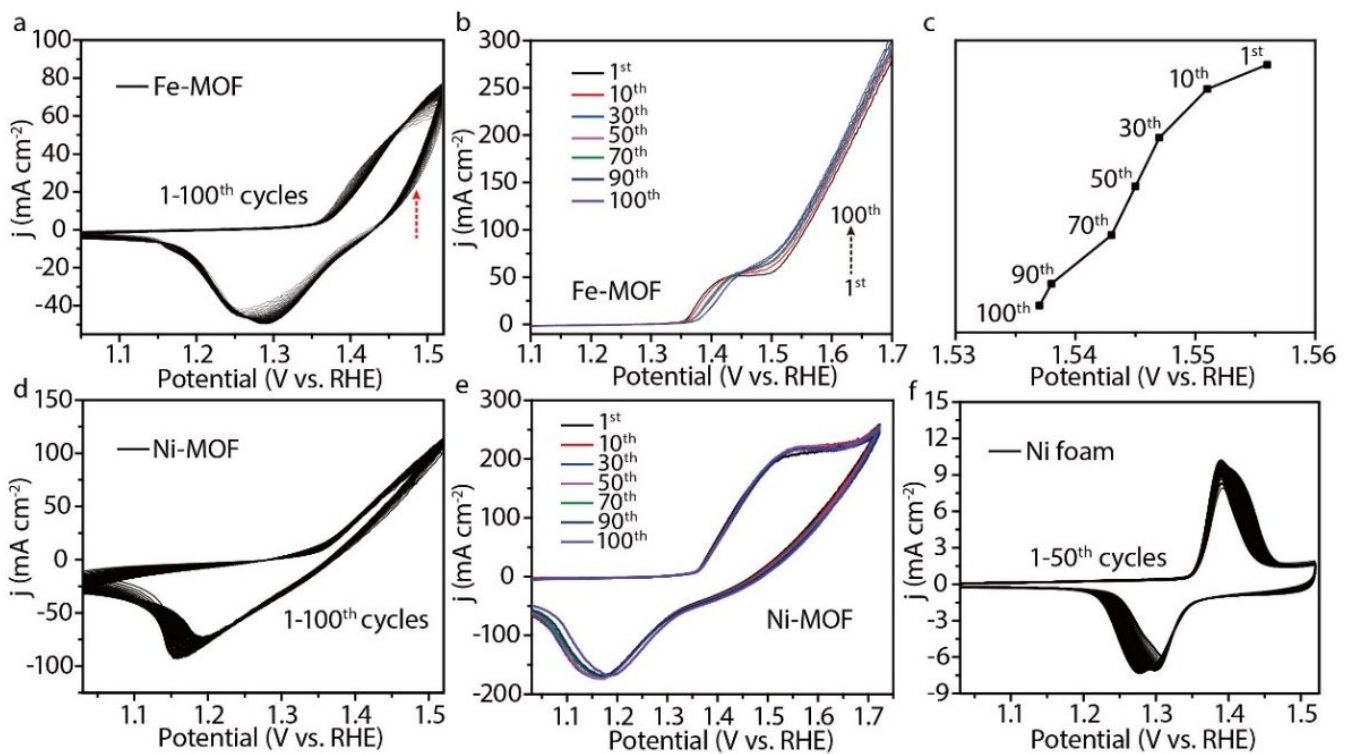

Figure S17. a) $100 \mathrm{CV}$ cycles between 1.02 and 1.52 versus RHE at a scan rate of $50 \mathrm{mV} \mathrm{s}^{-1}$ in $1 \mathrm{M} \mathrm{KOH}$ for Fe-MOFs. b) LSV curves with the increase of the CV cycles between 1.02 and $1.72 \mathrm{~V}$ versus RHE for Fe-MOFs. Scan rate: $5 \mathrm{mV} \mathrm{s}^{-1}$ c) Comparison of potentials with the increase of the $\mathrm{CV}$ cycles at a current density of $100 \mathrm{~mA} \mathrm{~cm}^{-2}$. d) $100 \mathrm{CV}$ cycles between 1.02 and $1.52 \mathrm{~V}$ versus RHE at a scan rate of $50 \mathrm{mV} \mathrm{s}^{-1}$ in $1 \mathrm{M} \mathrm{KOH}$ for Ni-MOFs. e) CV curves with the increase of the CV cycles between 1.02 and $1.72 \mathrm{~V}$ versus RHE for Ni-MOFs. Scan rate: $5 \mathrm{mV} \mathrm{s}^{-1} \mathrm{f}$ ) $100 \mathrm{CV}$ cycles between 1.02 and $1.52 \mathrm{~V}$ versus RHE at a scan rate of $50 \mathrm{mV}$ $\mathrm{s}^{-1}$ in $1 \mathrm{M} \mathrm{KOH}$ for nickel foam. 

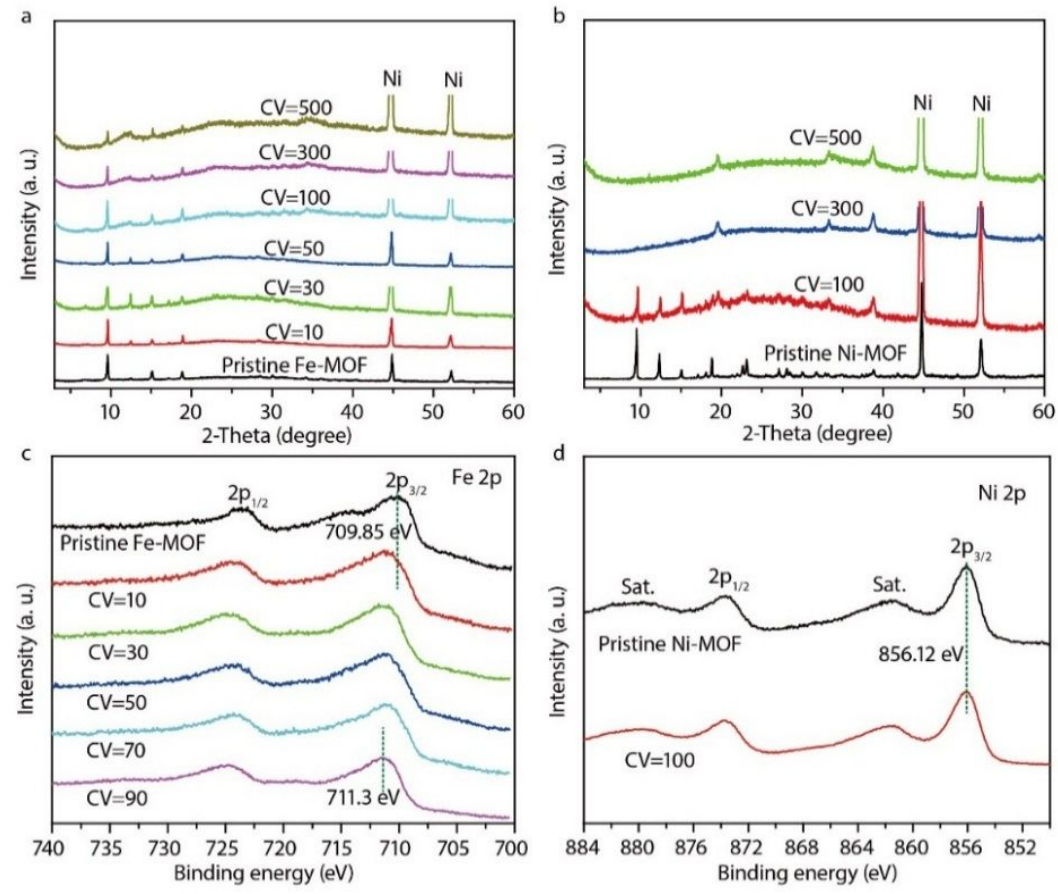

Figure S18. XRD patterns of a) Fe-MOF nanoarrays and b) Ni-MOF nanoarrays after different $\mathrm{CV}$ test. High-resolution XPS spectra of c) Fe 2p for Fe-MOFs and d) Ni 2p for Ni-MOFs after different $\mathrm{CV}$ test.
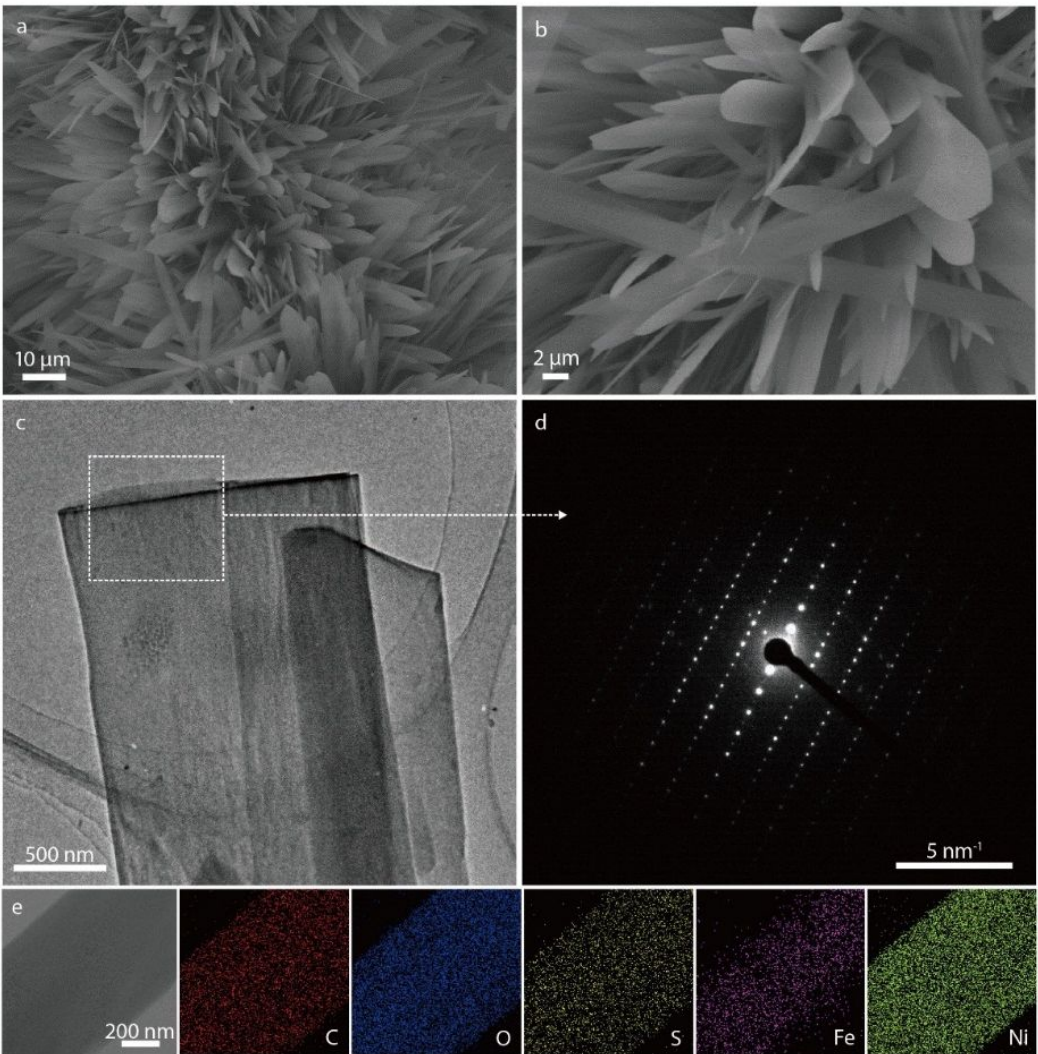

Figure S19. a, b) SEM images of $\mathrm{Fe}_{1} \mathrm{Ni}_{1}$-MOF nanoarrays grown on nickel foam with different magnifications. c) TEM image and d) SAED pattern for $\mathrm{Fe}_{1} \mathrm{Ni}_{1}$-MOFs. e) HAADF-STEM and the corresponding EDS elemental mapping images of $\mathrm{C}, \mathrm{O}, \mathrm{S}, \mathrm{Fe}$ and $\mathrm{Ni}$ elements for $\mathrm{Fe}_{1} \mathrm{Ni}_{1}$ MOF nanobelts. 


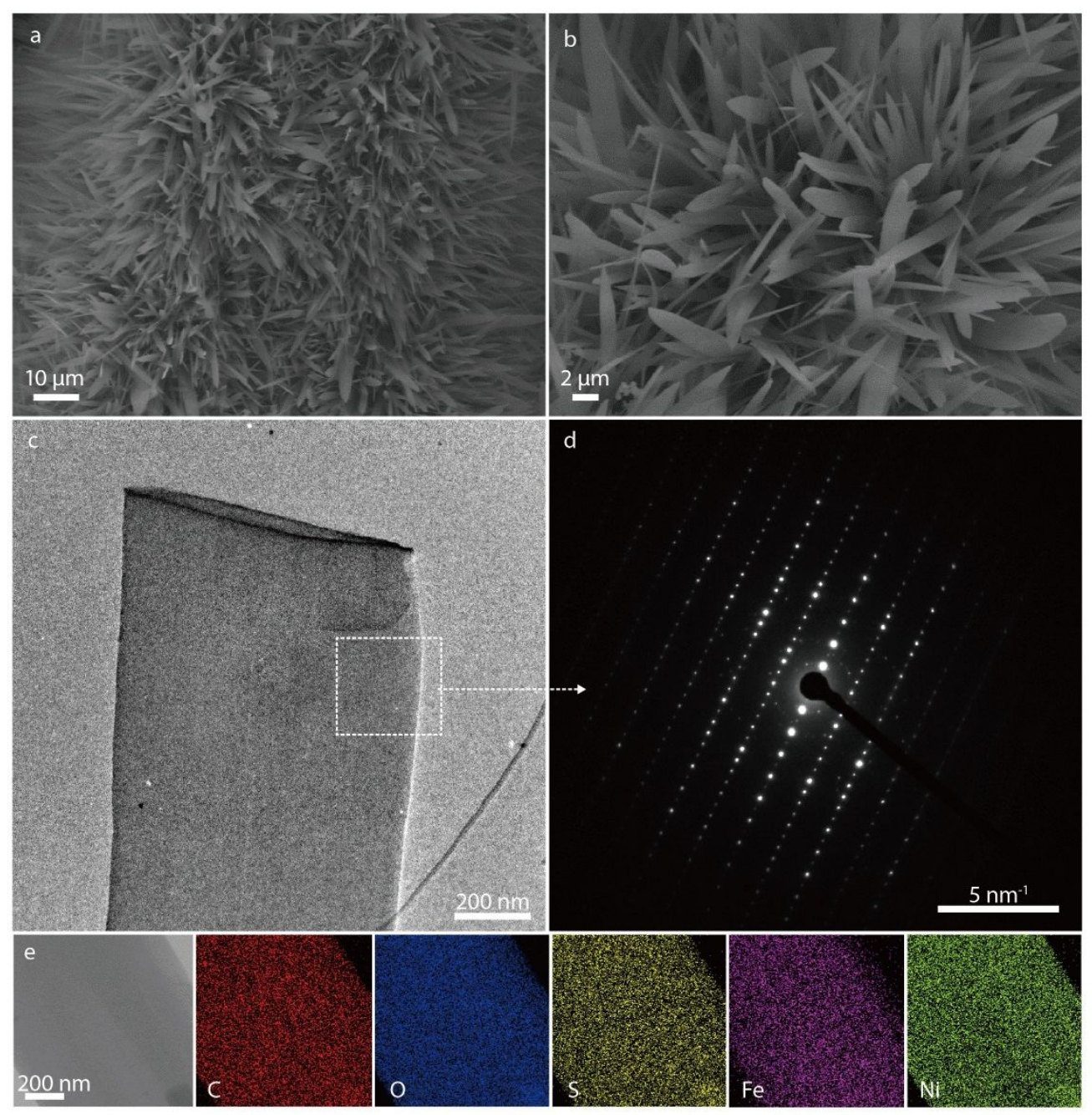

Figure $\mathrm{S} 20 . \mathrm{a}, \mathrm{b}) \mathrm{SEM}$ images of $\mathrm{Fe}_{3} \mathrm{Ni}_{1}$-MOF nanoarrays grown on nickel foam with different magnifications. c) TEM image and d) SAED pattern for $\mathrm{Fe}_{3} \mathrm{Ni}_{1}$-MOFs. e) HAADF-STEM and the corresponding EDS elemental mapping images of $\mathrm{C}, \mathrm{O}, \mathrm{S}, \mathrm{Fe}$ and $\mathrm{Ni}$ elements for $\mathrm{Fe}_{3} \mathrm{Ni}_{1}$ MOF nanobelts.
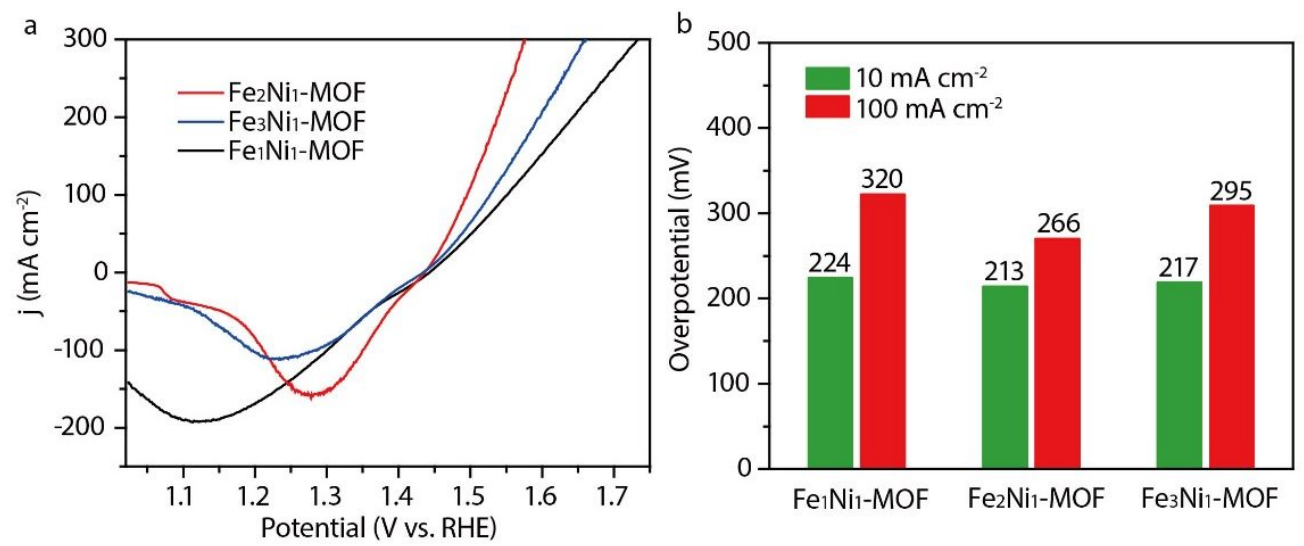

Figure S21. a) Polarization curves of $\mathrm{Fe}_{1} \mathrm{Ni}_{1}-\mathrm{MOFs}, \mathrm{Fe}_{2} \mathrm{Ni}_{1}-\mathrm{MOF}$ and $\mathrm{Fe}_{3} \mathrm{Ni}_{1}-\mathrm{MOF}$ in the reverse sweep direction. b) The comparison of overpotentials at 10 and $100 \mathrm{~mA} \mathrm{~cm}^{-2}$. 

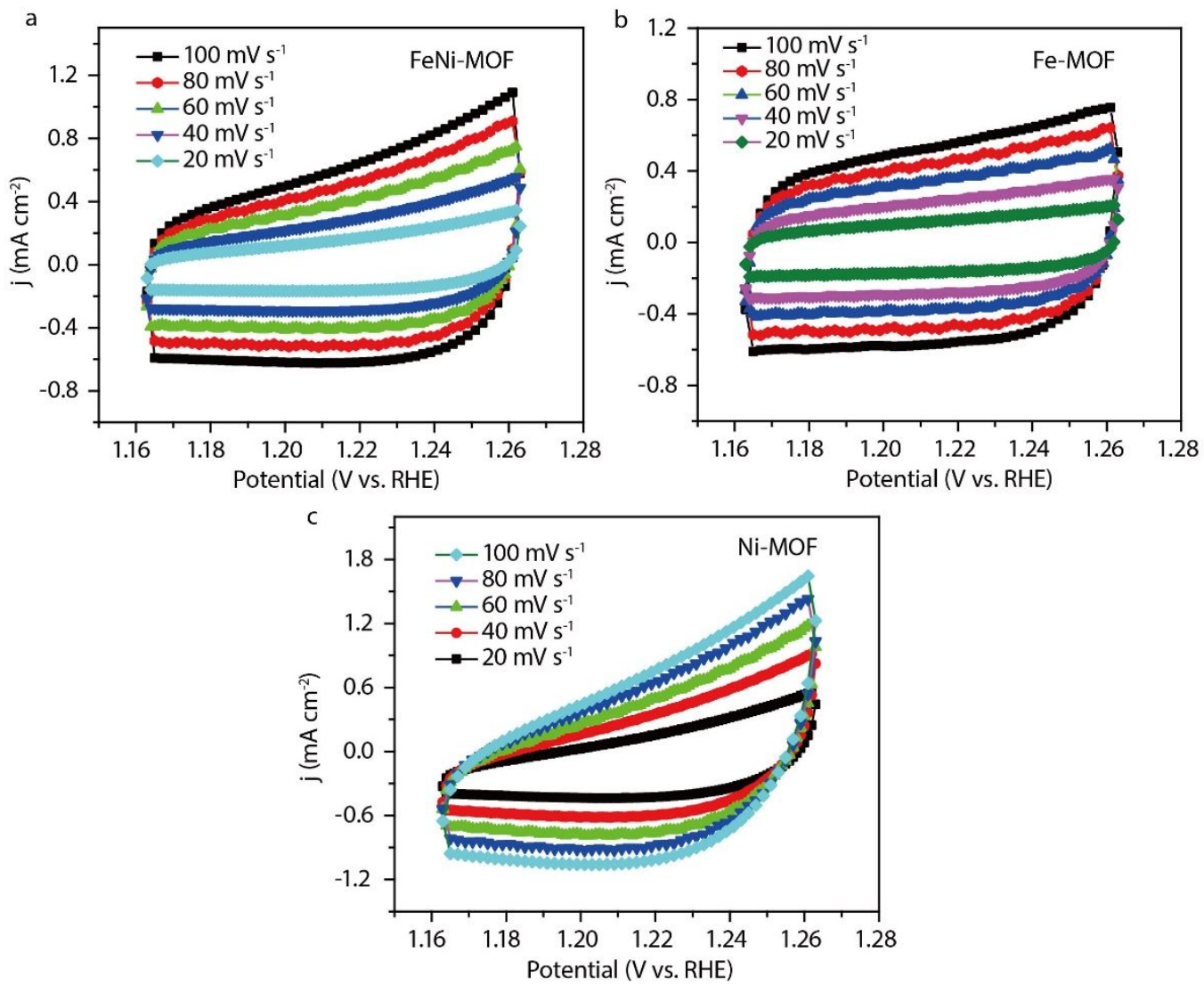

Figure S22. CV curves of a) FeNi-MOFs, b) Fe-MOFs and c) Ni-MOFs measured at different scan rates from 20 to $100 \mathrm{mV} \mathrm{s}^{-1}$.

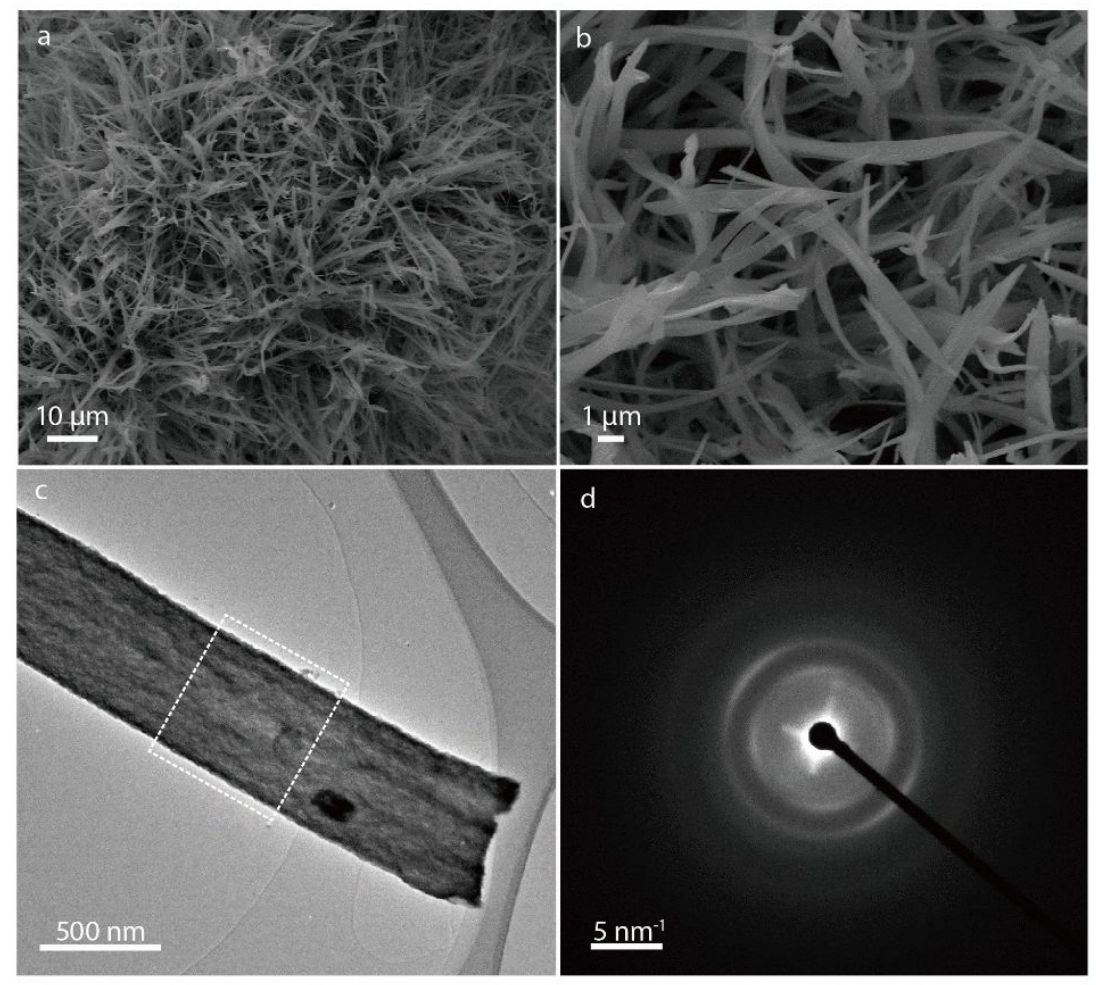

Figure S23. a-b) SEM, c) TEM images and d) the corresponding SAED of FeNi-MOFs after long-term OER durability test. 

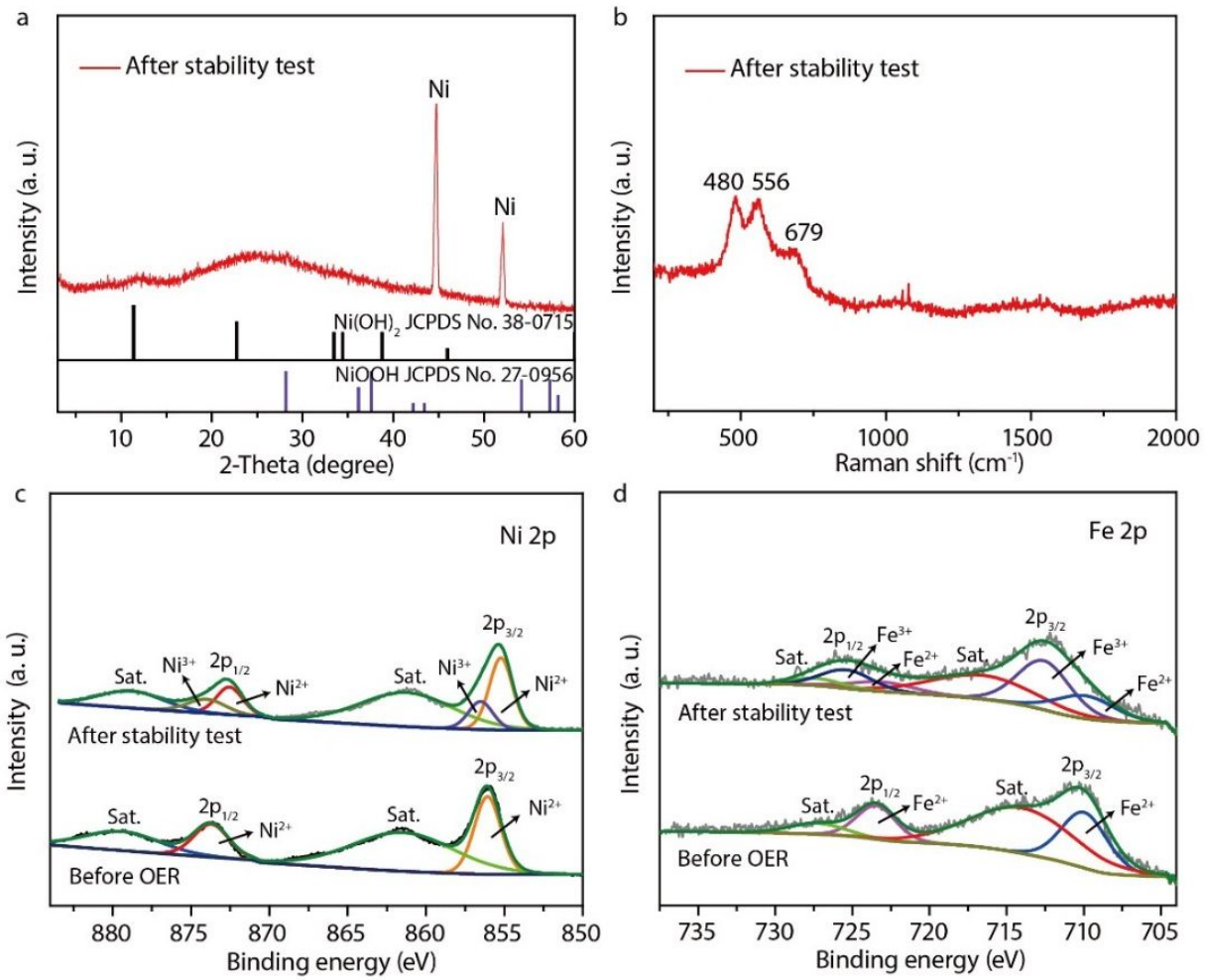

Figure S24. a) XRD, b) Raman, c) and d) XPS spectra of FeNi-MOFs after long-term OER durability test.
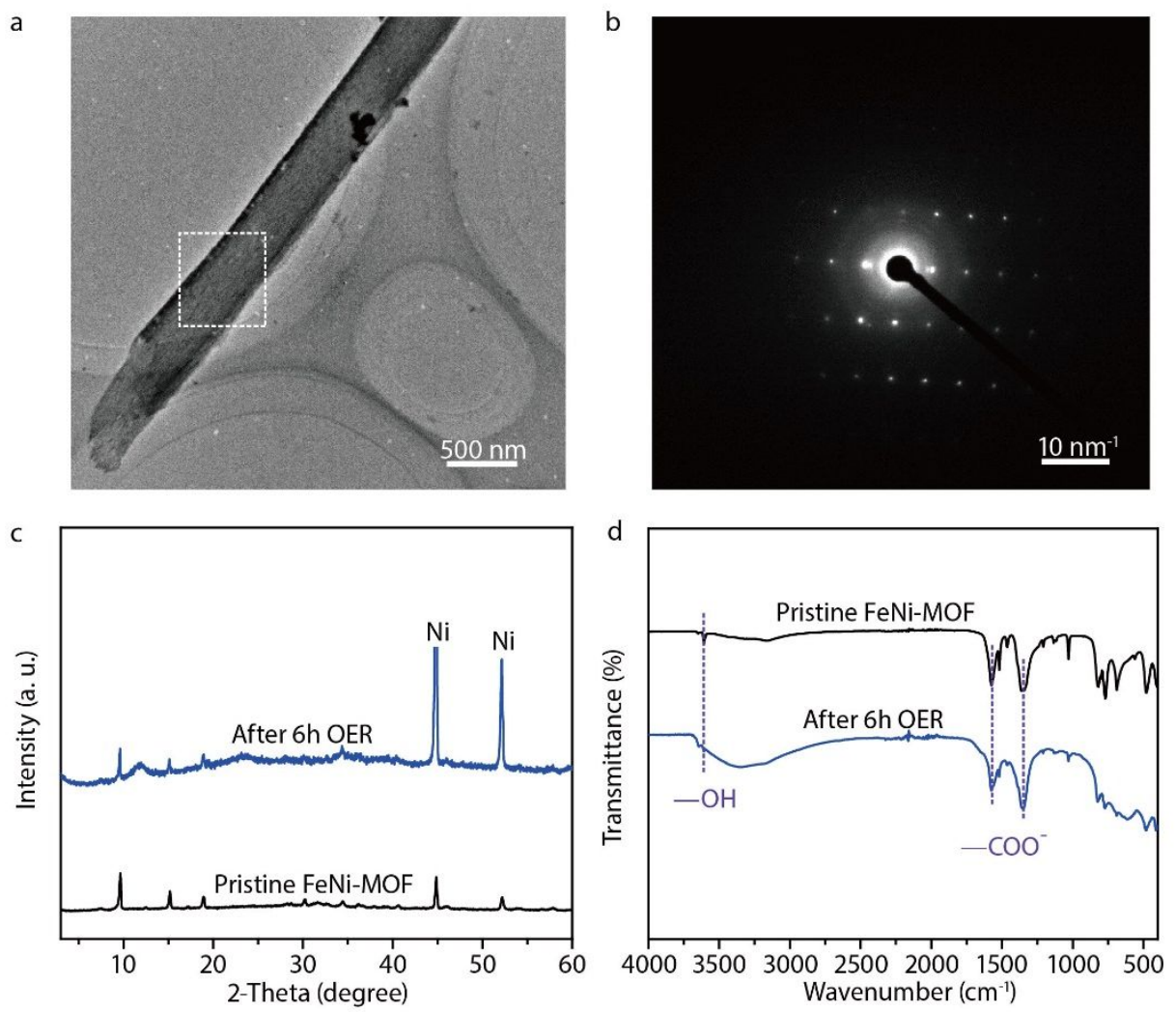

Figure S25. a) TEM image, b) the corresponding SAED pattern, c) XRD and d) FT-IR spectra of FeNi-MOFs after $6 \mathrm{~h}$ OER process. 
Table S1. The molar ratios of Fe/Ni in corresponding products (estimated with TEM EDX).

\begin{tabular}{ccc}
\hline Sample & $\begin{array}{c}\text { Feeding molar ratio } \\
(\text { Fe:Ni) }\end{array}$ & $\begin{array}{c}\text { Final product molar ratio } \\
(\text { Fe: } N i)\end{array}$ \\
\hline $\mathrm{Fe}_{1} \mathrm{Ni}_{1}$-MOFs & $1: 1$ & $1: 8.3$ \\
$\mathrm{Fe}_{2} \mathrm{Ni}_{1}$-MOFs & $2: 1$ & $1: 6.2$ \\
$\mathrm{Fe}_{3} \mathrm{Ni}_{1}-\mathrm{MOFs}$ & $3: 1$ & $1: 2.3$ \\
\hline
\end{tabular}

Table S2. The integrated area ratios of $\mathrm{Fe}^{3+} / \mathrm{Fe}^{2+}$ in $\mathrm{Fe} 2 \mathrm{p}_{3 / 2}$ based on the fitted XPS spectra.

\begin{tabular}{cc}
\hline Sample & $\mathrm{Fe}^{3+} / \mathrm{Fe}^{2+}$ \\
\hline $\mathrm{CV}=10$ & $2: 5$ \\
$\mathrm{CV}=30$ & $2.1: 5$ \\
$\mathrm{CV}=50$ & $3.2: 5$ \\
$\mathrm{CV}=70$ & $6.7: 5$ \\
$\mathrm{CV}=100$ & $8.9: 5$ \\
$\mathrm{CV}=300$ & $8.8: 5$ \\
\hline
\end{tabular}


Table S3. Comparison of the OER activity for various Fe/Ni-based or MOF-based electrocatalysts.

\begin{tabular}{|c|c|c|c|c|c|}
\hline Catalysts & $\begin{array}{l}\text { Overpotential } \\
(m V)\end{array}$ & $\begin{array}{l}\text { Tafel slope } \\
\left(m V \text { dec }^{-1}\right)\end{array}$ & Stability test & Electrolyte & $\operatorname{Ref}$ \\
\hline $\begin{array}{c}\text { FeNi- } \\
\text { MOFs/NF }\end{array}$ & $\begin{array}{l}213 @ 10 \mathrm{~mA} \mathrm{~cm}^{-2} \\
266 @ 100 \mathrm{~mA} \mathrm{~cm}^{-2}\end{array}$ & 52.4 & 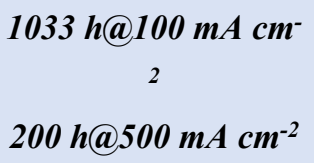 & 1 М КОН & This work \\
\hline NFN-MOF/NF & $290 @ 50 \mathrm{~mA} \mathrm{~cm} \mathrm{~cm}^{-2}$ & 58.8 & $30 h @ 500 m A c^{-2}$ & $1 \mathrm{M} \mathrm{KOH}$ & $\begin{array}{c}\text { Adv. Energy } \\
\text { Mater. 2018, } \\
\text { 8, } 1801065\end{array}$ \\
\hline $\begin{array}{l}\mathrm{Fe}_{0.1}-\mathrm{Ni}- \\
\mathrm{MOF} / \mathrm{NF}\end{array}$ & 263@100 mA cm-2 & 69.8 & $20 h @ 150 m A c^{-2}$ & $1 \mathrm{M} \mathrm{KOH}$ & $\begin{array}{c}\text { J. Mater. } \\
\text { Chem. A, } \\
2019,7,8771\end{array}$ \\
\hline $\begin{array}{c}\text { MCCF/NiMn- } \\
\text { MOFs }\end{array}$ & $280 @ 10 \mathrm{~mA} \cdot \mathrm{cm}^{-2}$ & 86 & $30 h @ 10 m A c m^{-2}$ & $1 \mathrm{M} \mathrm{KOH}$ & $\begin{array}{c}\text { Angew. } \\
\text { Chem. Int. } \\
\text { Ed. 2020, 59, } \\
1\end{array}$ \\
\hline $\begin{array}{l}\text { CoFe-PBA } \\
\text { NS@NF-24 }\end{array}$ & 256@10 mA $\mathrm{cm}^{-2}$ & 54 & 24 h@100 mA cm-2 & $1 \mathrm{M} \mathrm{KOH}$ & $\begin{array}{c}\text { Nano Energy } \\
2020,68 \\
104371\end{array}$ \\
\hline $\begin{array}{l}\text { MAF-X27- } \\
\mathrm{OH} / \mathrm{Cu} \text { foil }\end{array}$ & $338 @ 10 \mathrm{~mA} \cdot \mathrm{cm}^{-2}$ & 82 & $24 h @ 10 m A c m^{-2}$ & $1 \mathrm{M} \mathrm{KOH}$ & $\begin{array}{c}\text { J. Am. Chem. } \\
\text { Soc. } 2016, \\
138 \\
8336 .\end{array}$ \\
\hline $\begin{array}{c}\mathrm{Fe} / \mathrm{Ni}- \\
\mathrm{MOF} / \mathrm{NF}\end{array}$ & $300 @ 100 \mathrm{~mA} \mathrm{~cm}-2$ & 71.3 & $60 h @ 300 m V$ & $1 \mathrm{M} \mathrm{KOH}$ & $\begin{array}{l}\text { Angew. } \\
\text { Chem. Int. } \\
\text { Ed. 2018, } \\
\text { 130, } 1906\end{array}$ \\
\hline $\begin{array}{c}\mathrm{Ni@CoO@Co} \\
\mathrm{NC}\end{array}$ & 309@10 mA $\mathrm{cm}^{-2}$ & 53 & $20 h @ 309 m V$ & $1 \mathrm{M} \mathrm{KOH}$ & $\begin{array}{c}\text { Chem 2017, } \\
\text { 2, 791-802 }\end{array}$ \\
\hline $\mathrm{FeOOH}(\mathrm{Se}) / \mathrm{IF}$ & $364 @ 100 \mathrm{~mA} \cdot \mathrm{cm}^{-2}$ & 54 & $100 h @ 100 m A c^{-2}$ & $1 \mathrm{M} \mathrm{KOH}$ & $\begin{array}{c}\text { J. Am. Chem. } \\
\text { Soc. 2019, } \\
\text { 141, } 7005\end{array}$ \\
\hline $\begin{array}{c}\text { Ni-MOF@Fe- } \\
\text { MOF }\end{array}$ & 265@10 mA $\mathrm{cm}^{-2}$ & 82 & -- & $1 \mathrm{M} \mathrm{KOH}$ & $\begin{array}{l}\text { Adv. Funct. } \\
\text { Mater. 2018, } \\
28,1801554\end{array}$ \\
\hline $\begin{array}{c}\text { Ni-Fe-MOFs } \\
\text { NSs }\end{array}$ & 221@10 mA cm-2 & 56.0 & $20 h @ 10 m A c m^{-2}$ & $1 \mathrm{M} \mathrm{KOH}$ & $\begin{array}{c}\text { Angew. } \\
\text { Chem. Int. } \\
\text { Ed. 2019, 58, } \\
1\end{array}$ \\
\hline
\end{tabular}




\begin{tabular}{|c|c|c|c|c|c|}
\hline NiFe Alloy & $242 @ 10 \mathrm{~mA} \cdot \mathrm{cm}^{-2}$ & 24 & $200 h @ 40 m A \mathrm{~cm}^{-2}$ & $1 \mathrm{M} \mathrm{KOH}$ & $\begin{array}{c}\text { Nano Lett. } \\
\text { 2020, 20, } \\
4278\end{array}$ \\
\hline $\begin{array}{c}\text { NiFe-MOF- } \\
\text { 74/NF }\end{array}$ & 223@10 $\mathrm{mA} \cdot \mathrm{cm}^{-2}$ & 71.6 & $65 h @ 230 m V$ & $1 \mathrm{M} \mathrm{KOH}$ & $\begin{array}{c}\text { Chem. } \\
\text { Commun., } \\
\text { 2018, 54, } \\
7046\end{array}$ \\
\hline $\begin{array}{l}\text { FeNi-PPy } \\
\text { HNSs/NF }\end{array}$ & 273@100 mA cm-2 & 40.9 & $10 h @ 100 m A c^{-2}$ & $1 \mathrm{M} \mathrm{KOH}$ & $\begin{array}{c}\text { Appl. Catal. } \\
\text { B. 2020, 274, } \\
119112\end{array}$ \\
\hline $\begin{array}{c}\mathrm{Co} / \mathrm{Ni}(\mathrm{BDC})_{2} \mathrm{~T} \\
\mathrm{ED} @ \mathrm{CF}\end{array}$ & 287@50 mA cm $\mathrm{cm}^{-2}$ & 76.2 & $25 h @ 50 m A c^{-2}$ & $1 \mathrm{M} \mathrm{KOH}$ & $\begin{array}{c}\text { J. Mater. } \\
\text { Chem. A. } \\
\text { 2019, 7, } 18519\end{array}$ \\
\hline NF@Ni/C-600 & $353 @ 50 \mathrm{~mA} \mathrm{~cm} \mathrm{~cm}^{-2}$ & 54 & $70 h @ 1.6 V$ & $1 \mathrm{M} \mathrm{KOH}$ & $\begin{array}{c}\text { Energy } \\
\text { Environ. Sci., } \\
2018,11, \\
2363\end{array}$ \\
\hline $\begin{array}{c}\text { Ni:- } \\
\text { FeOOH/NGF }\end{array}$ & 214@10 $\mathrm{mA} \cdot \mathrm{cm}^{-2}$ & 36.2 & $60 h @ 300 m A c^{-2}$ & $1 \mathrm{M} \mathrm{KOH}$ & $\begin{array}{c}\text { ACS Catal. } \\
2019,9,5025\end{array}$ \\
\hline
\end{tabular}

NF: Ni foam CF: Cu foam MCCF: multi-channel carbon fibers NGF: N-doped graphite foam

IF: Iron foam 